\title{
Molecular Mechanisms Underlying Pluripotency and Lineage Commitment - The Role of GSK-3
}

\author{
Bradley W. Doble ${ }^{1}$, Kevin F. Kelly ${ }^{1}$ and James R. Woodgett ${ }^{2}$ \\ ${ }^{1}$ McMaster University Stem Cell and Cancer Research Institute, Hamilton, Ontario \\ ${ }^{2}$ Samuel Lunenfeld Research Institute, Mount Sinai Hospital, Toronto, Ontario
}

Canada

\section{Introduction}

The highly related serine/threonine kinases GSK3a and GSK3 $\beta$ are transducers of Wnt/ $\beta$ catenin, PI-3K, Notch and Hedgehog signalling pathways, placing them at the hub of key developmental and metabolic processes. There is accumulating evidence suggesting that GSK-3 inhibitors aid in the acquisition or sustenance of pluripotency in embryonic stem cells of mouse, rat and human origin. However, the mechanism through which GSK-3 inhibitors impart their effects is unclear due to the myriad cellular processes in which GSK-3 plays a role. Here, we review the studies that have examined the consequences of GSK-3 inhibition in pluripotent stem cells with a focus on key signalling pathways, which have been implicated in GSK-3 inhibitor-mediated effects.

\section{Overview of GSK-3 $\alpha$ and GSK-3 $\beta$ structure and function}

Glycogen synthase kinase-3 is a serine/threonine protein kinase, which was named based on its ability to phosphorylate and inhibit glycogen synthase, the rate-limiting enzyme of glycogen synthesis (Embi et al., 1980; Woodgett et al., 1983). Mammals express two homologues of GSK-3, GSK-3 $\alpha$ and GSK-3 $\beta$, which are encoded by separate genes (Woodgett, 1990). Throughout this chapter we will use "GSK-3" to refer to both GSK-3 $\alpha$ and GSK-3 $\beta$. The two GSK-3 gene products share almost identical kinase domains, but differ substantially at their amino and carboxy termini. Notably, GSK-3a has a glycine-rich Nterminal extension, which is not present in GSK-3 $\beta$. This is reflected in the relative molecular masses of GSK-3 $\alpha$ and GSK-3 $\beta$, with GSK-3 $\alpha$ having a predicted MW of $51 \mathrm{kDa}$, and GSK-3 $\beta$ having a slightly lower MW of $47 \mathrm{kDa}$ (see Fig. 1).

Both enzymes retain activity when their non-catalytic N-terminal extensions are deleted, whereas truncation mutants of their disparate non-catalytic C-terminal sequences display reduced activity, in part due to improper folding (Buescher and Phiel, 2010). There is a splice variant of GSK-3 $\beta$ (GSK-3 $\beta 2$ ), which has a 13 amino acid insert in the kinase domain (Mukai et al., 2002; Schaffer et al., 2003). The GSK-3 $\beta 2$ variant is less abundant than the GSK$3 \beta 1$ variant. Even in the brain, where it is most enriched, GSK-3 $\beta 2$ protein levels are still approximately 2 - to 3 -fold less than those of GSK-3 $\beta 1$. GSK-3 $\beta 2$ displays reduced activity towards some substrates (e.g. Tau, CRMP2, CRMP4, phospho-GS2, Inhibitor-2) when compared to the GSK-3 $\beta 1$ variant, although some substrates (e.g. c-Myc and c-Jun) appear to 
be equivalently phosphorylated by either GSK-3 $\beta$ isoform (Mukai et al., 2002; Soutar et al., 2010).

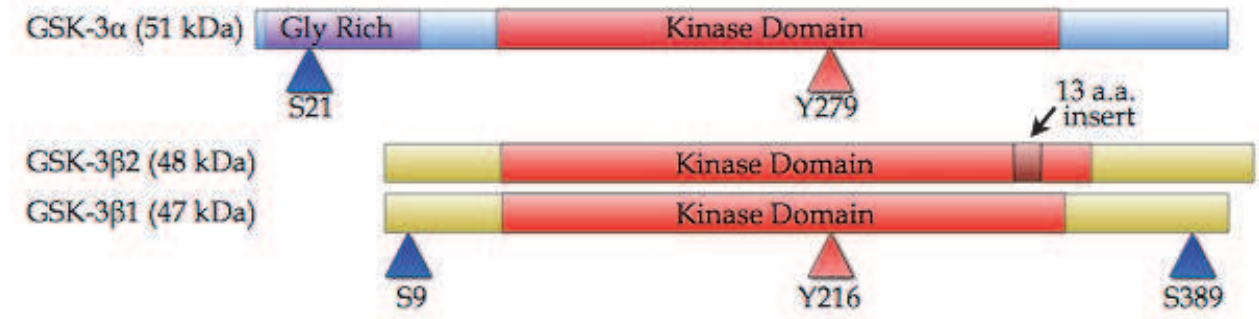

Fig. 1. Schematic depiction of GSK-3 $\alpha$ and GSK-3 $\beta$ proteins. Red shaded triangles indicate the sites of tyrosine phosphorylation required for maximal catalytic activity. Blue shaded triangles point to sites of inhibitory phosphorylation.

GSK-3 is unusual in that it exhibits a preference for substrates that are pre-phosphorylated by another kinase at a position located four residues C-terminal to the GSK-3 target site (Fiol et al., 1987). Thus, the consensus sequence for a GSK-3 substrate is S/T-X-X-X-S-P/T-P, where the first serine or threonine (S/T) is the GSK-3 target site, $\mathrm{X}$ is any amino acid, and the final S/T residue is the site that is phosphorylated by a priming kinase. The GSK-3 substrates CRMP2 and CRMP4 deviate from the usual consensus sequence in that the number of residues between the priming site and the GSK-3 target site is four, instead of the usual three (Cole et al., 2004). Thus, the GSK-3 substrate consensus sequence is not invariant. Frequently, GSK-3 substrates contain several tandem target residues, spaced such that after an initial priming phosphorylation, GSK-3 will phosphorylate multiple consecutive target sites located N-terminal to the priming site, with GSK-3 acting as the priming kinase for each subsequent phosphorylation event. There are hundreds of potential GSK-3 substrates with properly spaced tandem GSK-3 target sites, based on bioinformatics analyses (Taelman et al., 2010), although less than 100 GSK-3 substrates have been reported in the literature and only a subset of these has been thoroughly validated.

Nascent GSK-3 $\alpha$ and GSK-3 $\beta$ enzymes, as they fold into their final conformation, undergo a transient state in which they act as tyrosine kinases, serving to autophosphorylate themselves on a key tyrosine residue (Lochhead et al., 2006). The resultant phosphorylation on tyrosine 216 of GSK-3 $\beta$ or the equivalent tyrosine 279 of GSK-3 $\alpha$ is required for full serine/threonine kinase activity of the fully mature enzymes. Subsequent kinase activity is specific for serine/threonine phosphorylation. In the absence of signals, that is, resting conditions, GSK-3 exhibits a high degree of activity. The primary mode of regulating GSK-3 is via inactivation, which can be accomplished through phosphorylation, protein-protein interactions or sequestration.

\subsection{Regulation of GSK-3 activity through phosphorylation by upstream kinases. 2.1.1 Inhibitory N-terminal phosphorylation}

When serine 9 of GSK-3 $\beta$ (or serine 21 of GSK-3 $\alpha$ ) is phosphorylated, it mimicks a primed, intramolecular pseudosubstrate that acts in cis as a competitive inhibitor of GSK-3 activity (Cross et al., 1995). The crystal structure of GSK-3 $\beta$ revealed that the negatively charged phosphate on primed substrates fits into a pocket of positively charged residues in the 
substrate binding cleft of the kinase, thereby placing the substrate into the proper orientation for GSK-3-mediated phosphorylation (Bax et al., 2001; Dajani et al., 2001; ter Haar et al., 2001). This pocket also binds the phosphorylated N-terminal peptide of GSK-3 when it is phosphorylated at S9/S21 - competing out exogenous substrates and hence, interfering with activity. There are several kinases capable of inhibiting GSK-3 through S9/S21 phosphorylation, including PKB/Akt, p70 ribosomal S6 kinase, p90 ribosomal S6 kinase, protein kinase A and certain protein kinase Cs (Cross et al., 1995; Fang et al., 2000; Goode et al., 1992; Sutherland and Cohen, 1994; Torres et al., 1999).

\subsubsection{Inhibitory C-terminal phosphorylation (GSK-3 $\beta$-specific)}

Phosphorylation of serine 389 (S389), which is located near the carboxy terminus of mouse GSK-3 $\beta$ (threonine 390 is the equivalent residue in human GSK-3 $\beta$ ), is also capable of generating a pseudosubstrate inhibitor of GSK-3 $\beta$ activity in a manner analogous to that obtained through phosphorylation of S9 (Thornton et al., 2008). There is no equivalent residue to S389 found in the sequence of GSK-3 $\alpha$, thus, S389 phosphorylation provides a mechanism through which GSK-3 $\beta$ activity may be differentially regulated from GSK3- $\alpha$ activity. The only kinase that has been linked to S389 phosphorylation to date is p38 MAPK, which appears to phosphorylate S389 in brain and thymocytes (Thornton et al., 2008).

\subsection{Regulation through multi-protein complexes}

GSK-3 can also be regulated through interactions with other proteins. This is most clearly demonstrated in the canonical Wnt/ $\beta$-catenin signaling pathway where GSK-3 binds several proteins with distinct functional consequences. Details of this signalling pathway are discussed in section 4.1. In a multi-protein assembly known as the $\beta$-catenin destruction complex, a high-affinity interaction between GSK-3 and the scaffolding protein Axin or Axin2/Conductin is required for GSK-3 to efficiently phosphorylate the substrate $\beta$-catenin (Behrens et al., 1998; Hart et al., 1998; Ikeda et al., 1998a). GSK-3 interacts strongly with members of the GSK-3 binding protein (GBP)/FRAT family of proteins and these interactions were thought to compete with Axin/Axin2 interactions with GSK-3 as part of the mechanism of Wnt/ $\beta$-catenin signalling [reviewed in: (van Amerongen and Berns, 2005)]. However, loss-of-function studies in mice indicate that the FRAT proteins are dispensable for $\mathrm{Wnt} / \beta$-catenin signalling in mammals, given the lack of any obvious phenotype in triple knockout FRAT1,2,3-null mice (Van Amerongen, 2005). GSK-3 also interacts with the intracellular domain of LRP6, a co-receptor for Wnt/ $\beta$-catenin signalling (Beagle et al., 2009; Mi et al., 2006; Piao et al., 2008; Wu et al., 2009). A model has been proposed in which Wnt ligand-induced phosphorylation of the intracellular domain of LRP6 results in GSK-3 binding and inactivation, thereby inhibiting GSK-3-mediated $\beta$-catenin phosphorylation (Wu et al., 2009).

\subsection{Functional redundancy of GSK-3 $\alpha$ and GSK-3 $\beta$}

As described above, the kinase domains of GSK-3a and GSK-3 $\beta$ are virtually identical, resulting in a high degree of functional overlap between the two proteins. For instance, with respect to the role of GSK-3 in Wnt/ $\beta$-catenin signalling, there is clear functional redundancy between GSK-3 $\alpha$ and GSK-3 $\beta$, based on genetic studies in mouse embryonic stem cells (Doble et al., 2007). Still, there are striking differences in the phenotypes of mice lacking GSK-3a or GSK-3 $\beta$. GSK-3a knockout mice are viable but insulin-sensitized 
(MacAulay et al., 2007) and they display abnormal brain structure and behaviour (Kaidanovich-Beilin et al., 2009) as well as progressive cardiac hypertrophy and contractile dysfunction (Zhou et al., 2010). By contrast, GSK-3 $\beta$ knockout mice are inviable (Hoeflich et al., 2000). These animals die either prior to, or immediately after, birth and display cardiovascular developmental defects and liver degeneration (Hoeflich et al., 2000; Kerkela et al., 2008). It is currently unclear whether the different phenotypes arise due to different expression patterns of GSK-3 $\alpha$ and GSK-3 $\beta$ (both isoforms are expressed in most tissues examined) or distinct subsets of substrates (although few, if any, substrates have been shown to be targeted by only one of the two isoforms).

\section{Pathways and transcription factors that regulate pluripotency in mouse and human pluripotent stem cells}

Stems cells are defined by their ability to self-renew (i.e. to make more stem cells) while retaining the ability to differentiate into one or more specialized cell types. Embryonic stem cells (ESCs) have the ability to differentiate into all cell types of the embryo proper (Evans and Kaufman, 1981; Rossant, 2001). In other words, they are pluripotent, a remarkable property that has obvious implications for tissue replacement therapies targetting diseased or damaged tissues. To retain their stem cell identity, both embryonic and adult stem cells (such as hematopoietic stem cells) have active signalling pathways that regulate their proliferation and pluripotency (reviewed in: (Molofsky et al., 2004)). In ESCs, self-renewal depends on the maintenance of a transcriptional program regulated, minimally, by a set of three transcription factors. These factors comprise the core transcriptional program responsible for the maintenance of mouse ES cell pluripotency and include; Oct-4, Sox-2 and Nanog (Boyer et al., 2005; Chew et al., 2005; Loh et al., 2006; Rodda et al., 2005).

The most commonly used media for maintaining mouse ESCs under serum-free conditions require supplementation with leukemia inhibitory factor (LIF) and bone morphogenetic protein-4 (BMP4), which initiate signalling through gp130/STAT- and Smad-mediated pathways, respectively (Niwa et al., 1998; Ying et al., 2003; Ying and Smith, 2003). Notably, these signalling molecules/pathways are incapable of maintaining undifferentiated human ESCs in vitro (Daheron et al., 2004; Humphrey et al., 2004; Xu et al., 2002). Feeder-free culture of human ESCs requires Activin/Nodal and FGF-2 supplementation instead (Beattie et al., 2005; James et al., 2005; Levenstein et al., 2006; Ludwig et al., 2006; Vallier et al., 2005). Despite a requirement for activation of ostensibly different signalling pathways, the transcriptional mediators of pluripotency appear to be similar in both human and mouse ESCs (Boyer et al., 2005; Chew et al., 2005; Loh et al., 2006; Rodda et al., 2005) with Nanog playing a central role (Pan and Thomson, 2007).

The difference in the medium requirements for mouse versus human ESCs (mESCs vs hESCs) likely reflects dissimilar developmental origins. There are two primary lines of evidence supporting the notion that hESCs represent a more advanced stage of development than the early blastocysts from which mESCs are obtained: i. Pluripotent mouse epiblast stem cells (EpiSCs), derived from an embryo at a later developmental stage than that typically used to obtain mESCs, have the same growth factor requirements (Activin/Nodal and FGF-2) as human "ESCs" (Brons et al., 2007; Tesar et al., 2007). ii. Human ESCs or induced pluripotent stem cells can attain a mESC-like, LIF-dependent state, if they are reprogrammed with pluripotency-inducing transcription factors in the presence of LIF (Buecker et al., 2010; Hanna et al., 2010). The pluripotent state of rodent 
EpiSCs (and primate "ESCs") differs biochemically and epigenetically from that of true rodent ESCs; the two conditions have been termed primed and naïve pluripotent states, respectively (Nichols and Smith, 2009).

Of note, inactivation of GSK-3 through the use of small molecule inhibitors enhanced the maintenance of human pluripotent stem cells or pluripotent stem cells derived from the NOD strain of mouse in a naïve pluripotent state (Hanna et al., 2010; Hanna et al., 2009). Furthermore, the "ground state" of naïve pluripotency in mESCs can be maintained with fully defined serum-free medium by adding a combination of three small-molecule inhibitors (3i): SU5402 and PD184352, which serve to inhibit mitogen-activated protein kinase (MAPK) signaling; and CHIR99021, a high-specificity GSK-3 inhibitor (Ying et al., 2008). A proposed mechanism of the $3 \mathrm{i}$ cocktail is that inhibition of MAPK signalling blocks autoinductive FGF4 signalling required for mESC differentiation, while GSK-3 inhibition may play a role in allowing undifferentiated mESCs to survive and proliferate.

\section{Effects of GSK-3 inhibition/ablation on pluripotent stem cells}

There are now several reports in which inhibition of GSK-3 through the use of small molecules (e.g. CHIR99021 or BIO) has been shown to enhance the maintenance and derivation of embryonic stem cells obtained from mice, including the problematic C57BL/ 6 strain, from which de novo mESC cell line generation had been very difficult (Gertsenstein et al., 2010; Kiyonari et al., 2010; Sato et al., 2009). Furthermore, inhibition of GSK-3 has facilitated the isolation of rat ESCs, which had also been technically challenging (Buehr et al., 2008; Li et al., 2009). In the following sections, we provide an overview of the potential mechanisms through which GSK-3 inhibition imparts its effects on pluripotency.

\subsection{The central role of GSK-3 in Wnt/ $\beta$-catenin signalling}

The Wnt family of secreted glycoproteins regulates cellular interactions during Wnt signalling and is involved in the genesis of a variety of human cancers, including those of the colon, liver and breast (Giles et al., 2003; Morin and Weeraratna, 2003). In the canonical Wnt/ $\beta$-catenin pathway, the ultimate outcome of ligand-initiated signal transduction is largely dependent on the activation of genes regulated by T-cell factor (TCF) / lymphoid enhancer factor (LEF) transcription factors (Arce et al., 2006; Brantjes et al., 2002). TCF/LEF proteins, in the absence of a Wnt signal, repress transcription in conjunction with corepressors such as members of the Groucho/TLE (Transducin-like Enhancer of split) family (Chen and Courey, 2000; Hurlstone and Clevers, 2002). In response to Wnt, newly accumulated $\beta$-catenin displaces Groucho/TLE from TCF/LEF and acts as a co-activator of TCF/LEF to initiate transcription (Brantjes et al., 2002; Chen and Courey, 2000; Daniels and Weis, 2005). There are four mammalian TCF/LEF family members: TCF1, LEF1, TCF3 and TCF4 (Arce et al., 2006). In mESCs, transcripts from all of the TCF/LEF genes are readily detected, but those encoding TCF3 predominate at steady state (Anton et al., 2007; Pereira et al., 2006). At the protein level, all TCF/LEF family members are readily detected by western blot analyses of mESC lysates (Kelly et al., 2011). TCF3 has been shown to negatively regulate the transcription of Nanog (Pereira et al., 2006; Yi et al., 2008) and to co-occupy promoters with Nanog and Oct-4 in mESCs (Cole et al., 2008).

GSK-3 plays a central role in the canonical Wnt/ $\beta$-catenin signalling pathway (see Fig. 2), serving to keep steady state levels of the cytoplasmic, signalling pool of $\beta$-catenin low in the 
absence of Wnt ligands (Dominguez et al., 1995; He et al., 1995; Peifer et al., 1994). A fraction of GSK-3 is complexed with the scaffolding proteins adenomatous polyposis coli (APC) and Axin1 (or Axin2), and efficiently phosphorylates $\beta$-catenin ["primed" by casein kinase-1 (CK1)] on a series of N-terminal domain residues earmarking it for polyubiquitination and proteasomal degradation (Doble and Woodgett, 2003). GSK-3 also phosphorylates APC and Axin, increasing their affinities for $\beta$-catenin (Hoeflich et al., 2000; Ikeda et al., 1998b; Jho et al., 1999; Yamamoto et al., 1999).

Activation of Wnt/ $\beta$-catenin signalling requires two types of receptors. The first class belongs to a sub-family of single-pass transmembrane receptors, the low-density lipoprotein receptor related proteins (LRPs), LRP5 and LRP6 (He et al., 2004; Schweizer and Varmus, 2003; Tamai et al., 2000; Wehrli et al., 2000). The second type of receptor comprises a family of serpentine 7pass transmembrane receptors known as Frizzleds (Fz)(Logan and Nusse, 2004; Orsulic and Peifer, 1996), which appear to function as G protein-coupled receptors (Katanaev et al., 2005; Liu et al., 2005; Schulte and Bryja, 2007). The binding of Wnt to Fz/LRP6 results in the recruitment of a trimolecular complex of Dishevelled, Axin and GSK-3 to the Fz/LRP6 heterodimer (Bilic et al., 2007; Zeng et al., 2008; Zeng et al., 2005). GSK-3 and CKI then phosphorylate residues of LRP6 to create an Axin docking site which enhances Axin's affinity for LRP6 and results in inhibition of the $\beta$-catenin destruction complex in an unclear manner, possibly involving direct GSK-3 inhibition through Axin-binding (Zeng et al., 2008; Zeng et al., 2005) and/or interactions with phospho-LRP6 (Wu et al., 2009). The reorganization of Axin upon LRP5/ 6 binding may also trigger sequestration of Axin-associated GSK-3 into multivesicular endosomes - preventing direct access to $\beta$-catenin (Taelman et al., 2010).

\subsubsection{Wnt/ $\beta$-catenin signalling reinforces the pluripotent state of $\mathrm{mESCs}$}

The first study to directly implicate GSK-3 and Wnt/ $\beta$-catenin signalling in the regulation of ESC pluripotency suggested that human and mouse ESCs respond similarly to activation of Wnt/ $\beta$-catenin signalling (Sato et al., 2004). By using a reporter construct harbouring TCF binding sites driving yellow fluorescent protein (YFP) expression, pathway activation was found to be highest in undifferentiated mESCs and was gradually lost as the cells differentiated, suggesting that endogenous $\beta$-catenin/TCF signalling supported the maintenance of pluripotency. Activation of the Wnt pathway in mESCs or hESCs, by treatment with either Wnt3a or the GSK-3 inhibitor BIO, prolonged the retention of pluripotency markers, although one caveat of this study is that these cells were not examined for more than 5-7 days, over multiple passages (Sato et al., 2004). Similar observations were made in mESCs treated with the GSK-3 inhibitor, LiCl (Anton et al., 2007), as well as Wnt-conditioned medium (Hao et al., 2006; Ogawa et al., 2006; Singla et al., 2006). As an aside, there is a fundamental difference between treatment with GSK-3 inhibitors and treatment with Wnt due to the inherent feedback control circuitry of Wnt signalling. Hence, the target genes of $\beta$-catenin include Axin2 and DKK1 which both act to reduce Wnt signalling. However, inhibition of GSK-3 short-circuits these controls leading to chronic activation of $\beta$-catenin signalling that is more reminiscent of tumours that harbour APC deletions or $\beta$-catenin mutations.

Some of the conclusions reached by Sato et al. conflict with an independent study investigating the effects of Wnt pathway manipulation in hESCs over multiple weeks (Dravid et al., 2005). In this study, addition of the Wnt antagonists Dkk1 or sFRP2 did not compromise the self-renewal ability of hESCs when cultured on a feeder layer, nor did the 
inclusion of recombinant Wnt3a support hESC propagation in the undifferentiated state in the absence of feeders. $\beta$-catenin/TCF activity increased significantly after BMP-4- or retinoic acid-induced hESC differentiation, supporting a pro-differentiation role for the Wnt pathway in hESCs (Dravid et al., 2005). Indeed, sustained Wnt pathway activation or GSK-3 inhibition in monolayer culture promotes hESC and $\mathrm{mESC}$ differentiation into mesoendodermal progenitors, which are capable of enhanced endothelial and cardiac specification (Bakre 2007). A bisindoylmaleimide GSK-3 inhibitor, designated 1m, which was shown to sustain pluripotency of mESCs (Bone et al., 2009), by contrast, has been shown to be effective in differentiating hESCs into definitive endoderm (Bone et al., 2011). These divergent effects of $1 \mathrm{~m}$-mediated GSK-3 inhibition are likely due to the caveats associated with the developmental origins of human and mouse ESCs, discussed in section 3 above.

\subsubsection{Genetic Gain- and Loss-of-function studies of Wnt pathway regulators in ESCs}

\subsubsection{1 mESCS with mutant Adenomatous polyposis coli (Apc) display impaired differentiation}

The scaffolding protein Adenomatous polyposis coli (Apc) is a key negative regulator of the Wnt/ $\beta$-catenin pathway that is frequently mutated in human cancers, particularly those of the colon (Kwong and Dove, 2009). Kielman et al. used teratoma assays in syngeneic mice to evaluate the differentiation capacities of mESCs harbouring a spectrum of mutant forms of Apc (Kielman et al., 2002). These mutants exhibit varying abilities to regulate $\beta$-catenin levels, with some (i.e. Apc $\mathrm{MIN}^{\mathrm{MIN}}$ ) being completely deficient in this regard, while others (i.e. Apc ${ }^{1638 N / 1638 N}$ ) retaining about $50 \%$ activity (Kielman et al., 2002). Interestingly, these cells exhibit a range of differentiation defects, with those harbouring the most disruptive Apc mutations having the most profound deficiencies. Although Apc ${ }^{\mathrm{MIN}} / \mathrm{MIN}$ mESCs fail to form teratomas, Apc $1638 \mathrm{~N} / 1638 \mathrm{~N}$ teratomas fail to generate detectable neural tissue, cartilage and bone. These observations carried over to in vitro analyses: upon LIF withdrawal, only the most severe Apc mutant lines retained an undifferentiated morphology. Dysregulation of $\beta$-catenin levels was implicated as the mechanism underlying the differentiation blockade, since mESCs with a targeted deletion of $\beta$-catenin exon 3, which encodes the GSK3 phosphorylation sites and so generates a stabilized form of the protein, also failed to differentiate (Kielman et al., 2002).

\subsubsection{Ectopic expression of $\beta$-catenin reinforces pluripotency}

A caveat of studies relying solely on GSK-3 inhibitors and/or Wnt stimulation is that such treatments can have pleiotropic effects that are not limited to $\beta$-catenin stabilization due to the many other targets of GSK-3. To directly examine whether increased $\beta$-catenin levels are sufficient to reinforce pluripotency, the effects of wild type and stabilized $\beta$-catenin overexpression were examined using an inducible system in mESCs (Ogawa et al., 2006). In this system, the expression of stabilized $\beta$-catenin, and to a lesser extent wild type $\beta$-catenin, prolonged the retention of an undifferentiated ESC morphology after LIF removal. This effect may be attributable, at least in part, to crosstalk between $\beta$-catenin and LIF/Stat3 signalling, since GSK-3 inhibition using BIO activated a Stat3 reporter construct (Ogawa et al., 2006). Takao et al. (2007) obtained similar results by expressing stabilized (S33A) $\beta$ catenin in mESCs, transiently selecting the cells for expression of puromycin resistance, and assaying for the retention of pluripotency markers after LIF withdrawal (Takao et al., 2007). Finally, our group demonstrated that mESCs stably expressing the S33A form of $\beta$-catenin 
exhibits enhanced self-renewal and delayed loss of pluripotency (Kelly et al., 2011). Intriguingly, similar results were observed using a deletion mutant of $\beta$-catenin lacking its C-terminal transactivation domain, which transactivates $\beta$-catenin/TCF target genes with $\sim 10 \%$ the efficiency of the full length form, suggesting that sustenance of pluripotency by $\beta$ catenin occurs independently of TCF proteins.

One possible mechanism through which stabilized $\beta$-catenin could restrict exit from pluripotent state is through the direct modulation of the pluripotency regulators. In support of such a mechanism, the formation of $\beta$-catenin/Oct- 4 complexes was implicated in the regulation of Nanog expression (Takao et al., 2007). Indeed, $\beta$-catenin/Oct- 4 complexes were detected by co-immunoprecipitation using DKO mESC lysates, or wild type mESCs lysates after stimulation of the Wnt- $\beta$-catenin pathway using Wnt3a or GSK-3 inhibition. Furthermore, an established Oct reporter [PORE; (Botquin et al., 1998)] and specific Oct-4 target genes were induced after pathway stimulation, supporting a mechanism whereby $\beta$ catenin enhances Oct-4-mediated transcriptional activation (Kelly et al., 2011).

$\beta$-catenin also exerts some of its effects on ESCs through its function as a structural protein (see Fig. 2). The role of $\beta$-catenin in the cadherin/catenin complex has historically been a structural one, to "hardwire" the cadherin complex to the actin cytoskeleton (Nelson, 2008). More recently, this view has been called into question, owing to controversial studies proposing that a tripartite cadherin/ $\beta$-catenin/actin complex does not form in vivo (Drees et al., 2005; Yamada et al., 2005). Nonetheless, analyses of $\beta$-catenin knockout mice strongly support its role as a key regulator of cadherin-mediated cell-cell adhesion (Haegel et al., 1995; Huelsken et al., 2000). Ablation of $\beta$-catenin causes embryonic lethality at $\sim \mathrm{d} 6.5$, with the mutant embryos exhibiting defects in formation of embryonic ectoderm (Haegel et al., 1995), as well as anterior-posterior axis formation (Huelsken et al., 2000). Interestingly, expression levels and adherens junction localization of the $\beta$-catenin-related protein plakoglobin appear increased in $\beta$-catenin $(-/)$ embryos, suggesting that plakoglobin at least partly rescues adhesion defects caused by $\beta$-catenin deficiency (Huelsken et al., 2000). $\beta$ catenin $(-/)$ mESCs cultured in LIF-containing medium express markedly lower levels of Rex1 transcript when compared to wild type mESCs, suggesting that these cells are prone to spontaneous differentiation (Anton et al., 2007). In support of this possibility, the expression of pluripotency markers is more rapidly lost in these cells after retinoic acid-induced differentiation (Wagner et al., 2010).

The dual roles of $\beta$-catenin have been re-examined recently by using genetic "rescue" experiments in Ctnnb1-deficient mESCs with a deletion of exons 3-6 ( $\beta$-catenin $\Delta / \Delta)$ (Lyashenko et al., 2011). In mESCs lacking endogenous full-length $\beta$-catenin, plakoglobin partially compensates for the loss of $\beta$-catenin with respect to its cell adhesion functions in undifferentiated mESCs. Under standard mESC culture conditions, global gene transcript expression profiles of wild-type and $\beta$-catenin knockout mESCs were almost identical, with no observed differences in the transcript levels of the pluripotency factors: Nanog, Oct4, Sox 2 or Rex1. Despite their normal appearance, $\beta$-catenin ${ }^{\Delta / \Delta} \operatorname{mESCs}$ were impaired in their ability to differentiate into mesendoderm and neuronal cell types. Stable re-expression of full-length or truncated $\beta$-catenin lacking its transactivation domain, in $\beta$-catenin ${ }^{\Delta / \Delta} \mathrm{mESCs}$, was able to rescue their ability to differentiate into definitive endoderm and neuronal cells.

\subsubsection{Generation and analysis of mouse embryonic stem cells lacking GSK-3}

Although GSK-3 inhibition is strongly implicated in the sustenance of pluripotency through the use of small molecular inhibitors, some of these inhibitors are known to elicit off-target 

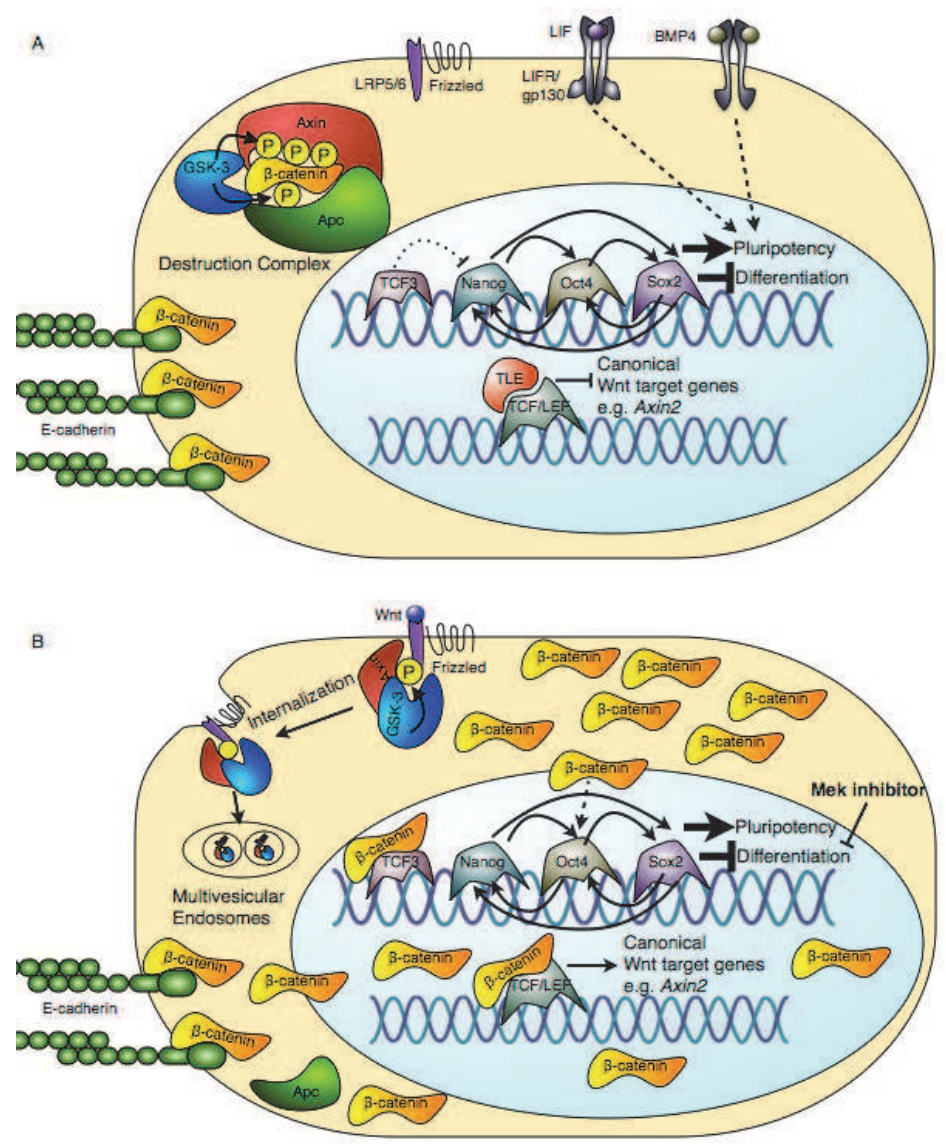

Fig. 2. Model illustrating the central role of $\beta$-catenin in mediating the pluripotencyenhancing effects of Wnt signaling (or GSK-3 inhibition/ablation) in mESCs. A. In the absence of Wnt, $\beta$-catenin is phosphorylated by GSK-3 in a "destruction complex", which tags it for proteosomal degradation. Levels of cytosolic and nuclear $\beta$-catenin are very low and canonical target genes are repressed via TCF/LEF factor interactions with TLE repressors. TCF3 exerts a weak repressive effect on Nanog gene expression but LIF and BMP supplementation are sufficient to prevent differentiation and ensure that the network of pluripotent transcription factors (Oct4, Sox 2 and Nanog) supports pluripotency. B) In the presence of Wnt, $\beta$-catenin is no longer targeted for degradation as the destruction complex is disrupted and GSK-3 is sequestered in multivesicular endosomes (see text for details). $\beta$ catenin accumulates in the cytosol and translocates to the nucleus where it activates canonical Wnt $/ \beta$-catenin target genes and associates with Oct- 4 complexes. $\beta$-catenin also de-represses TCF3 targets such as Nanog through a mechanism that does not require its transactivation domain. Inhibition of Mek signal transduction, together with Wnt treatment (or GSK-3 inhibition) are sufficient to maintain mESCs in a pluripotent ground state. 
effects, which could confound the interpretation of results (Bain et al., 2007). To circumvent such limitations, mouse embryonic stem cells lacking both alleles of GSK3 $\alpha$ and GSK-3 $\beta$ (double knockout; DKO) were generated and characterized (Doble et al., 2007). The morphology of DKO mESCs is altered dramatically relative to the wild type line, as colonies closely resemble the compact, highly refractile morphology of mESCs treated with CHIR99021 (Kelly et al., 2011). These cells exhibit highly elevated levels of cytoplasmic and nuclear $\beta$-catenin and expression of several prototypical targets of the Wnt/ $\beta$-catenin pathway (axin2, brachyury and $c d x 1$ ) is strongly upregulated (Doble et al., 2007). One of the most striking consequences of GSK-3 ablation in mESCs is their profound inability to differentiate efficiently, particularly to the neurectoderm lineage. Using established differentiation assays such as embryoid bodies or teratomas, in striking contrast to wild type mESCs, DKO mESCs retain the expression of pluripotency markers (Oct-4, Nanog) and fail to express detectable amounts of neural markers, such as $\beta$-III-tubulin.

To determine whether this differentiation blockade was due to the hyperactivation of $\beta$ catenin/TCF target genes, the original DKO line was modified to allow for the site-specific integration of transgenes at the endogenous GSK-3 $\beta$ locus; thereafter, a dominant negative form of TCF4 (TCF4DN) was constitutively expressed from this locus under the control of the EF1 $\alpha$ promoter (Kelly et al., 2011). Surprisingly, although the expression of TCF4DN efficiently attenuated the activation of $\beta$-catenin/TCF target genes, these cells were not rescued with regard to their impaired neurectoderm differentiation. However, after normalization of $\beta$-catenin levels through the stable expression of $\beta$-catenin-specific shRNAs, these cells were capable of neurectoderm differentiation in teratoma assays. These findings suggested that $\beta$-catenin, independent of its role as a transactivator of TCF target genes, regulates the acquisition and maintenance of the pluripotent state (Kelly et al., 2011).

Recent studies by two groups have revealed that TCF3 is regulated by $\beta$-catenin in a somewhat atypical manner (Wray et al., 2011; Yi et al., 2011). Of the four TCF/LEF family members, TCF3 is unusual in that there is little evidence that $\beta$-catenin directly activates TCF3 target genes. In most contexts, the other TCF/LEF family members, upon binding $\beta$ catenin, recruit transcriptional activators to increase target gene transcription. In mESCs, $\beta$ catenin appears to alleviate the repression of Tcf3 on genes such as Nanog, without recruiting transactivating factors (Wray et al., 2011). Derepression of TCF3 by $\beta$-catenin appears to be a significant part of the mechanism through which GSK-3 inhibition exerts its effects on mESC pluripotency (see Fig. 2).

\subsection{PI3K signalling and GSK-3 inhibition}

\subsubsection{Signalling through $\mathrm{PI} 3 \mathrm{~K}$ and the sustenance of pluripotency}

The PI3K pathway regulates various cellular processes, ranging from cell motility to growth, proliferation, survival and metabolism [reviewed in: (Cully et al., 2006; Yuan and Cantley, 2008)]. PI3Ks comprise a family of lipid kinases that phosphorylate the 3 ' hydroxyl group of phosphoinositide lipids within membranes. After activation by upstream growth factors, cytokines and receptor tyrosine kinases (RTKs), PI3K phosphorylates $\mathrm{PIP}_{2}$, to form $\mathrm{PIP}_{3}$. This process is reversed by the tumour suppressor phosphatase and tensin homolog deleted on chromosome ten (PTEN), which dephosphorylates $\mathrm{PIP}_{3}$ back to $\mathrm{PIP}_{2}$, thus terminating the pathway. Upon generation, $\mathrm{PIP}_{3}$ propagates the signal by binding to the pleckstrin homology (PH) domain of several downstream effector proteins, including the key effector protein kinase phosphoinositide-dependent kinase 1 (PDK1) which targets a variety of 
members of the AGC family of protein-serine kinases including Protein Kinase B (PKB; also known as Akt), resulting in the activation of PKB through its phosphorylation on T308. PKB elicits diverse effects through its phosphorylation of many signalling intermediates, including GSK-3, the Foxo transcriptional regulators and modulators of apoptotic signalling pathways. Aberrant activation of the PI3K pathway is thought to be a key event in the genesis and maintenance of several types of human cancers and various components of this system are frequently mutated in tumours (Luo et al., 2003; Cully et al., 2006; Yuan and Cantley, 2008).

The first indications that PI3K signalling may regulate self-renewal arose from the realization that signalling through the LIF receptor subunit, gp130, elicits pleiotropic effects through modulation of various signalling pathways, including the Ras/MAPK, JAK/STAT and PI3K pathways (Boeuf et al., 1997; Boeuf et al., 2001; Ernst et al., 1996; Takahashi-Tezuka et al., 1998). Indeed, direct stimulation of mESCs with LIF induces robust PI3K pathway activation (as assessed through the phosphorylation of Akt/PKB on S473, GSK3 $\alpha / \beta$ on S21 and S9, respectively, and a downstream pathway target, ribosomal S6 kinase) (Paling et al., 2004). This effect is blocked by treatment with the PI3K inhibitor, LY294002, or after the expression of a dominant negative form of p85, the regulatory subunit of Class IA PI3Ks (Paling et al., 2004). Inhibition of PI3K activity by these means results in substantially reduced self-renewal of mESCs (Paling et al., 2004), by a mechanism that involves the regulation of Nanog expression (Kingham and Welham, 2009; Storm et al., 2007). Importantly, while treatment of mESCs with LY294002 blocks PI3K-mediated induction of Nanog expression, this effect is reversed by treatment with GSK-3 inhibitors, implicating GSK-3 in the regulation of self-renewal through the modulation of Nanog levels (Storm et al., 2007). More recently, by performing gene expression analyses on mESCs cultured in LIFcontaining media with and without PI3K pathway inhibition, Storm et al. identified putative target genes of PI3K signalling (Storm et al., 2009). The majority of identified gene changers $(\sim 73 \%)$ were downregulated after PI3K inhibition, indicating that they are normally transcriptionally increased downstream of PI3K signalling. As was observed for Nanog (Storm et al., 2007), GSK-3 inhibition using BIO de-repressed the expression of some PI3K targets (Shp-1 and 1700061G19Rik), though many appeared to be regulated in a GSK-3-independent manner (Storm et al., 2009). Interestingly, knockdown of one of the GSK-3 targets, the tyrosine phosphatase Shp-1, compromised ESC self-renewal capacity, an effect that may involve its desphosphorylation of Stat3 (Storm et al., 2009). The identification of additional Shp-1 substrates will help clarify its mechanism of action in ESCs.

To determine whether constitutive activation of PI3K signalling was sufficient to support ESC self-renewal in the absence of LIF, the effects of stably expressing a constitutively active form of PKB (myr-PKB) in ESCs were examined (Watanabe et al., 2006). Both mouse and monkey ESCs expressing myr-PKB retained expression of pluripotency markers (Oct-4, Nanog, Rex-1) after LIF withdrawal, indicating that PI3K activation can reinforce pluripotency under conditions permissive of differentiation (Watanabe et al., 2006). We have confirmed these findings using stable ESC lines expressing activated alleles of PKB and PDK1 (Ling et al. unpublished).

\subsubsection{Does PI3K signalling through GSK-3 modulate c-Myc stability to reinforce self- renewal?}

PI3K induced phosphorylation and inhibition of GSK-3 does not lead to increased stabilization of $\beta$-catenin (likely due to insulation of the relatively small fraction of GSK-3 
molecules associated with the Axin/ APC destruction complex) (Ng et al., 2009). A possible mechanism through which PI3K/GSK-3 signalling may regulate ESC self-renewal is through the regulation of c-Myc stability. As a target of LIF/Stat3 signalling, maintenance of c-Myc expression reinforces the pluripotent state of mESCs by suppressing differentiation (Cartwright et al., 2005). Upon LIF withdrawal, c-Myc transcript and protein levels in mESCs are sharply reduced, through a mechanism involving both its transcriptional repression and increased targeting for proteasomal degradation. However, ectopic expression of c-Myc harbouring the T58A mutation, abrogating a target site for GSK-3 phosphorylation that promotes ubiquitation and turnover, sustains pluripotency in the absence of LIF (Cartwright et al., 2005). In a follow-up study from the same group, it was suggested that GSK-3's ability to phosphorylate c-Myc relies upon its nuclear translocation. Upon LIF withdrawal of mESCs, GSK-3 localization shifts from the cytoplasm to the nucleus, thereby gaining access to c-Myc, and destabilizing it through phosphorylation on T58. Moreover, expression of activated PKB (myr-PKB), triggering GSK-3 inactivation through its phosphorylation at S21/S9, blocks GSK-3 nuclear translocation and c-Myc T58 phosphorylation/degradation (Bechard and Dalton, 2009). Taken together, downstream LIF signalling involving GSK-3-mediated stabilization of cMyc, may have a role in the regulation of ESC self-renewal.

\section{Conclusions/Future studies}

It is clear that in both human and mouse ESCs, inhibition of GSK-3 exerts strong effects on the biology of these unique cells. Whereas, in some contexts, GSK-3 inhibition promotes retention of naïve pluripotency, there are signalling environments in which GSK-3 inhibition promotes lineage-specific (mesendoderm) differentiation. Although we have focused on Wnt/ $\beta$-catenin and PI3K signalling, GSK-3 also plays a role in other developmentally important signalling pathways, such as the Hedgehog pathway [reviewed in: (Jiang and Hui, 2008)]. How GSK-3-mediated regulation of substrates beyond those in the Wnt and PI3K signalling pathways modulates ESC properties remains to be thoroughly investigated. Intriguingly, GSK-3 also appears to play a role in directing the expression of the de novo DNA methyltransferase Dnmt3a2, suggesting that GSK-3 may play a role in the regulation of the epigenome (Popkie et al., 2010). The role of GSK-3 in the epigenetic regulation of genes important for pluripotent stem cell self-renewal and differentiation is an exciting new direction for future studies.

\section{Acknowledgments}

We would like to acknowledge the Canadian Institutes of Health Research (JRW, BWD, KFK) and the Canada Research Chairs Program (BWD) for funding research from our laboratories that is cited in this chapter.

\section{References}

Van Amerongen, R., and Berns, A., (2005). Re-Evaluating the Role of Frat in Wnt-Signal Transduction. Cell Cycle 4, 1064-1072..

Anton, R., Kestler, H.A., and Kuhl, M. (2007). Beta-catenin signaling contributes to stemness and regulates early differentiation in murine embryonic stem cells. FEBS Lett 581, 5247-5254. 
Arce, L., Yokoyama, N.N., and Waterman, M.L. (2006). Diversity of LEF/TCF action in development and disease. Oncogene 25, 7492-7504.

Bain, J., Plater, L., Elliott, M., Shpiro, N., Hastie, C.J., McLauchlan, H., Klevernic, I., Arthur, J.S.C., Alessi, D.R., and Cohen, P. (2007). The selectivity of protein kinase inhibitors: a further update. The Biochemical Journal 408, 297-315.

Bax, B., Carter, P.S., Lewis, C., Guy, A.R., Bridges, A., Tanner, R., Pettman, G., Mannix, C., Culbert, A.A., Brown, M.J., et al. (2001). The structure of phosphorylated GSK-3beta complexed with a peptide, FRATtide, that inhibits beta-catenin phosphorylation. Structure 9, 1143-1152.

Beagle, B., Mi, K., and Johnson, G.V.W. (2009). Phosphorylation of PPP(S/T)P motif of the free LRP6 intracellular domain is not required to activate the Wnt/beta-catenin pathway and attenuate GSK3beta activity. Journal of Cellular Biochemistry 108, 886-895.

Beattie, G.M., Lopez, A.D., Bucay, N., Hinton, A., Firpo, M.T., King, C.C., and Hayek, A. (2005). Activin A maintains pluripotency of human embryonic stem cells in the absence of feeder layers. Stem Cells 23, 489-495.

Bechard, M., and Dalton, S. (2009). Subcellular localization of GSK3beta controls embryonic stem cell self-renewal. Mol Cell Biol. 29, 2092-104.

Behrens, J., Jerchow, B.A., Würtele, M., Grimm, J., Asbrand, C., Wirtz, R., Kühl, M., Wedlich, D., and Birchmeier, W. (1998). Functional interaction of an axin homolog, conductin, with beta-catenin, APC, and GSK3beta. Science 280, 596-599.

Bilic, J., Huang, Y.L., Davidson, G., Zimmermann, T., Cruciat, C.M., Bienz, M., and Niehrs, C. (2007). Wnt induces LRP6 signalosomes and promotes dishevelled-dependent LRP6 phosphorylation. Science 316, 1619-1622.

Boeuf, H., Hauss, C., Graeve, F.D., Baran, N., and Kedinger, C. (1997). Leukemia inhibitory factor-dependent transcriptional activation in embryonic stem cells. J Cell Biol 138, 1207-1217.

Boeuf, H., Merienne, K., Jacquot, S., Duval, D., Zeniou, M., Hauss, C., Reinhardt, B., HussGarcia, Y., Dierich, A., Frank, D.A., et al. (2001). The ribosomal $S 6$ kinases, cAMPresponsive element-binding, and STAT3 proteins are regulated by different leukemia inhibitory factor signaling pathways in mouse embryonic stem cells. J Biol Chem 276, 46204-46211.

Bone, H.K., Damiano, T., Bartlett, S., Perry, A., Letchford, J., Ripoll, Y.S., Nelson, A.S., and Welham, M.J. (2009). Involvement of GSK-3 in regulation of murine embryonic stem cell self-renewal revealed by a series of bisindolylmaleimides. Chem Biol 16, 15-27.

Bone, H.K., Nelson, A.S., Goldring, C.E., Tosh, D., and Welham, M.J. (2011). A novel chemically directed route for the generation of definitive endoderm from human embryonic stem cells based on inhibition of GSK-3. Journal of Cell Science.124, 1992-2000.

Botquin, V., Hess, H., Fuhrmann, G., Anastassiadis, C., Gross, M.K., Vriend, G., and Schöler, H.R. (1998). New POU dimer configuration mediates antagonistic control of an osteopontin preimplantation enhancer by Oct-4 and Sox-2. Genes \& Development 12, 2073-2090.

Boyer, L.A., Lee, T.I., Cole, M.F., Johnstone, S.E., Levine, S.S., Zucker, J.P., Guenther, M.G., Kumar, R.M., Murray, H.L., Jenner, R.G., et al. (2005). Core transcriptional regulatory circuitry in human embryonic stem cells. Cell 122, 947-956.

Brantjes, H., Barker, N., van Es, J., and Clevers, H. (2002). TCF: Lady Justice casting the final verdict on the outcome of Wnt signalling. Biological Chemistry 383, 255-261.

Brons, I.G.M., Smithers, L.E., Trotter, M.W.B., Rugg-Gunn, P., Sun, B., Chuva de Sousa Lopes, S.M., Howlett, S.K., Clarkson, A., Ährlund-Richter, L., Pedersen, R.A., et al. 
(2007). Derivation of pluripotent epiblast stem cells from mammalian embryos. Nature 448, 191-195.

Buecker, C., Chen, H.-H., Polo, J.M., Daheron, L., Bu, L., Barakat, T.S., Okwieka, P., Porter, A., Gribnau, J., Hochedlinger, K., et al. (2010). A Murine ESC-like State Facilitates Transgenesis and Homologous Recombination in Human Pluripotent Stem Cells. Cell Stem Cell 6, 535-546.

Buehr, M., Meek, S., Blair, K., Yang, J., Ure, J., Silva, J., Mclay, R., Hall, J., Ying, Q., and Smith, A.G. (2008). Capture of Authentic Embryonic Stem Cells from Rat Blastocysts. Cell 135, 1287-1298.

Buescher, J.L., and Phiel, C.J. (2010). A noncatalytic domain of glycogen synthase kinase-3 (GSK-3) is essential for activity. J Biol Chem 285, 7957-7963.

Cartwright, P., McLean, C., Sheppard, A., Rivett, D., Jones, K., and Dalton, S. (2005). LIF/STAT3 controls ES cell self-renewal and pluripotency by a Myc-dependent mechanism. Development 132, 885-896.

Chen, G., and Courey, A.J. (2000). Groucho/TLE family proteins and transcriptional repression. Gene 249, 1-16.

Chew, J.L., Loh, Y.H., Zhang, W., Chen, X., Tam, W.L., Yeap, L.S., Li, P., Ang, Y.S., Lim, B., Robson, P., et al. (2005). Reciprocal transcriptional regulation of Pou5f1 and Sox2 via the Oct4/Sox2 complex in embryonic stem cells. Mol Cell Biol 25, 6031-6046.

Cole, A.R., Knebel, A., Morrice, N.A., Robertson, L.A., Irving, A.J., Connolly, C.N., and Sutherland, C. (2004). GSK-3 phosphorylation of the Alzheimer epitope within collapsin response mediator proteins regulates axon elongation in primary neurons. J Biol Chem 279, 50176-50180.

Cole, M.F., Johnstone, S.E., Newman, J.J., Kagey, M.H., and Young, R.A. (2008). Tcf3 is an integral component of the core regulatory circuitry of embryonic stem cells. Genes Dev 22, 746-755.

Cross, D.A., Alessi, D.R., Cohen, P., Andjelkovich, M., and Hemmings, B.A. (1995). Inhibition of glycogen synthase kinase-3 by insulin mediated by protein kinase B. Nature 378, 785-789.

Cully, M., You, H., Levine, A.J., and Mak, T.W. (2006). Beyond PTEN mutations: the PI3K pathway as an integrator of multiple inputs during tumorigenesis. Nature Rev. Cancer 6, 184-192.

Daheron, L., Opitz, S.L., Zaehres, H., Lensch, W.M., Andrews, P.W., Itskovitz-Eldor, J., and Daley, G.Q. (2004). LIF/STAT3 signaling fails to maintain self-renewal of human embryonic stem cells. Stem Cells 22, 770-778.

Dajani, R., Fraser, E., Roe, S.M., Young, N., Good, V., Dale, T.C., and Pearl, L.H. (2001). Crystal structure of glycogen synthase kinase 3 beta: structural basis for phosphateprimed substrate specificity and autoinhibition. Cell 105, 721-732.

Daniels, D.L., and Weis, W.I. (2005). Beta-catenin directly displaces Groucho/TLE repressors from Tcf/Lef in Wnt-mediated transcription activation. Nat Struct Mol Biol 12, 364371.

Doble, B.W., Patel, S., Wood, G.A., Kockeritz, L.K., and Woodgett, J.R. (2007). Functional redundancy of GSK-3alpha and GSK-3beta in Wnt/beta-catenin signaling shown by using an allelic series of embryonic stem cell lines. Dev Cell 12, 957-971.

Doble, B.W., and Woodgett, J.R. (2003). GSK-3: tricks of the trade for a multi-tasking kinase. J Cell Sci 116, 1175-1186.

Dominguez, I., Itoh, K., and Sokol, S.Y. (1995). Role of glycogen synthase kinase 3 beta as a negative regulator of dorsoventral axis formation in Xenopus embryos. Proc Natl Acad Sci U S A 92, 8498-8502. 
Dravid, G., Ye, Z., Hammond, H., Chen, G., Pyle, A., Donovan, P., Yu, X., and Cheng, L. (2005). Defining the role of Wnt/beta-catenin signaling in the survival, proliferation, and self-renewal of human embryonic stem cells. Stem Cells (Dayton, Ohio) 23, 1489-1501.

Drees, F., Pokutta, S., Yamada, S., Nelson, W.J., and Weis, W.I. (2005). Alpha-catenin is a molecular switch that binds E-cadherin-beta-catenin and regulates actin-filament assembly. Cell 123, 903-915.

Embi, N., Rylatt, D.B., and Cohen, P. (1980). Glycogen synthase kinase-3 from rabbit skeletal muscle. Separation from cyclic-AMP-dependent protein kinase and phosphorylase kinase. Eur J Biochem 107, 519-527.

Ernst, M., Oates, A., and Dunn, A.R. (1996). Gp130-mediated signal transduction in embryonic stem cells involves activation of Jak and Ras/mitogen-activated protein kinase pathways. J Biol Chem 271, 30136-30143.

Evans, M.J., and Kaufman, M.H. (1981). Establishment in culture of pluripotential cells from mouse embryos. Nature 292, 154-156.

Fang, X., Yu, S.X., Lu, Y., Bast, R.C., Woodgett, J.R., and Mills, G.B. (2000). Phosphorylation and inactivation of glycogen synthase kinase 3 by protein kinase A. Proc Natl Acad Sci U S A 97, 11960-11965.

Fiol, C.J., Mahrenholz, A.M., Wang, Y., Roeske, R.W., and Roach, P.J. (1987). Formation of protein kinase recognition sites by covalent modification of the substrate. Molecular mechanism for the synergistic action of casein kinase II and glycogen synthase kinase 3. J Biol Chem 262, 14042-14048.

Gertsenstein, M., Nutter, L.M.J., Reid, T., Pereira, M., Stanford, W.L., Rossant, J., and Nagy, A. (2010). Efficient generation of germ line transmitting chimeras from C57BL/6N ES cells by aggregation with outbred host embryos. PLoS ONE 5, e11260.

Giles, R.H., van Es, J.H., and Clevers, H. (2003). Caught up in a Wnt storm: Wnt signaling in cancer. Biochim Biophys Acta 1653, 1-24.

Goode, N., Hughes, K., Woodgett, J.R., and Parker, P.J. (1992). Differential regulation of glycogen synthase kinase-3 beta by protein kinase C isotypes. J Biol Chem 267, 16878-16882.

Haegel, H., Larue, L., Ohsugi, M., Fedorov, L., Herrenknecht, K., and Kemler, R. (1995). Lack of beta-catenin affects mouse development at gastrulation. Development 121, 35293537.

Hanna, J., Cheng, A.W., Saha, K., Kim, J., Lengner, C.J., Soldner, F., Cassady, J.P., Muffat, J., Carey, B.W., and Jaenisch, R. (2010). Human embryonic stem cells with biological and epigenetic characteristics similar to those of mouse ESCs. Proc Natl Acad Sci U S A 107, 9222-9227.

Hanna, J., Markoulaki, S., Mitalipova, M., Cheng, A.W., Cassady, J.P., Staerk, J., Carey, B.W., Lengner, C.J., Foreman, R., Love, J., et al. (2009). Metastable pluripotent states in NOD-mouse-derived ESCs. Cell Stem Cell 4, 513-524.

Hao, J., Li, T.G., Qi, X., Zhao, D.F., and Zhao, G.Q. (2006). WNT/beta-catenin pathway upregulates Stat 3 and converges on LIF to prevent differentiation of mouse embryonic stem cells. Dev Biol 290, 81-91.

Hart, M.J., de los Santos, R., Albert, I.N., Rubinfeld, B., and Polakis, P. (1998). Downregulation of beta-catenin by human Axin and its association with the APC tumor suppressor, beta-catenin and GSK3 beta. Curr Biol 8, 573-581.

He, X., Saint-Jeannet, J.P., Woodgett, J.R., Varmus, H.E., and Dawid, I.B. (1995). Glycogen synthase kinase-3 and dorsoventral patterning in Xenopus embryos. Nature 374, 617622. 
He, X., Semenov, M., Tamai, K., and Zeng, X. (2004). LDL receptor-related proteins 5 and 6 in Wnt/beta-catenin signaling: arrows point the way. Development 131, 1663-1677.

Hoeflich, K.P., Luo, J., Rubie, E.A., Tsao, M.S., Jin, O., and Woodgett, J.R. (2000). Requirement for glycogen synthase kinase-3beta in cell survival and NF-kappaB activation. Nature 406, 86-90.

Huelsken, J., Vogel, R., Brinkmann, V., Erdmann, B., Birchmeier, C., and Birchmeier, W. (2000). Requirement for beta-catenin in anterior-posterior axis formation in mice. J Cell Biol 148, 567-578.

Humphrey, R.K., Beattie, G.M., Lopez, A.D., Bucay, N., King, C.C., Firpo, M.T., Rose-John, S., and Hayek, A. (2004). Maintenance of pluripotency in human embryonic stem cells is STAT3 independent. Stem Cells 22, 522-530.

Hurlstone, A., and Clevers, H. (2002). T-cell factors: turn-ons and turn-offs. Embo J 21, 23032311.

Ikeda, S., Kishida, S., Yamamoto, H., Murai, H., Koyama, S., and Kikuchi, A. (1998a). Axin, a negative regulator of the Wnt signaling pathway, forms a complex with GSK-3beta and beta-catenin and promotes GSK-3beta-dependent phosphorylation of betacatenin. EMBO J 17, 1371-1384.

Ikeda, S., Kishida, S., Yamamoto, H., Murai, H., Koyama, S., and Kikuchi, A. (1998b). Axin, a negative regulator of the Wnt signaling pathway, forms a complex with GSK-3beta and beta-catenin and promotes GSK-3beta-dependent phosphorylation of betacatenin. EMBO J 17, 1371-1384.

James, D., Levine, A.J., Besser, D., and Hemmati-Brivanlou, A. (2005). TGFbeta/activin/nodal signaling is necessary for the maintenance of pluripotency in human embryonic stem cells. Development (Cambridge, England) 132, 1273-1282.

Jho, E., Lomvardas, S., and Costantini, F. (1999). A GSK3beta phosphorylation site in axin modulates interaction with beta-catenin and Tcf-mediated gene expression. Biochem Biophys Res Commun 266, 28-35.

Jiang, J., and Hui, C.-C. (2008). Hedgehog signaling in development and cancer. Developmental Cell 15, 801-812.

Kaidanovich-Beilin, O., Lipina, T.V., Takao, K., van Eede, M., Hattori, S., Laliberté, C., Khan, M., Okamoto, K., Chambers, J.W., Fletcher, P.J., et al. (2009). Abnormalities in brain structure and behavior in GSK-3alpha mutant mice. Mol Brain 2, 35.

Katanaev, V.L., Ponzielli, R., Semeriva, M., and Tomlinson, A. (2005). Trimeric G proteindependent frizzled signaling in Drosophila. Cell 120, 111-122.

Kelly, K.F., Ng, D.Y., Jayakumaran, G., Wood, G.A., Koide, H., and Doble, B.W. (2011). $\beta$ catenin enhances Oct- 4 activity and reinforces pluripotency through a TCFindependent mechanism. Cell Stem Cell 8, 214-227.

Kerkela, R., Kockeritz, L., Macaulay, K., Zhou, J., Doble, B.W., Beahm, C., Greytak, S., Woulfe, K., Trivedi, C.M., Woodgett, J.R., et al. (2008). Deletion of GSK-3beta in mice leads to hypertrophic cardiomyopathy secondary to cardiomyoblast hyperproliferation. J Clin Invest 118, 3609-3618.

Kielman, M.F., Rindapaa, M., Gaspar, C., van Poppel, N., Breukel, C., van Leeuwen, S., Taketo, M.M., Roberts, S., Smits, R., and Fodde, R. (2002). Apc modulates embryonic stem-cell differentiation by controlling the dosage of beta-catenin signaling. Nat Genet 32, 594-605.

Kingham, E., and Welham, M.J. (2009). Distinct roles for isoforms of the catalytic subunit of class-IA PI3K in the regulation of behaviour of murine embryonic stem cells. J Cell Sci 122, 2311-21. 
Kiyonari, H., Kaneko, M., Abe, S.-I., and Aizawa, S. (2010). Three inhibitors of FGF receptor, ERK, and GSK3 establishes germline-competent embryonic stem cells of C57BL/6N mouse strain with high efficiency and stability. Genesis 48, 317-327.

Kwong, L.N., and Dove, W.F. (2009). APC and its modifiers in colon cancer. Advances in experimental medicine and biology 656, 85-106.

Levenstein, M.E., Ludwig, T.E., Xu, R.H., Llanas, R.A., VanDenHeuvel-Kramer, K., Manning, D., and Thomson, J.A. (2006). Basic fibroblast growth factor support of human embryonic stem cell self-renewal. Stem Cells 24, 568-574.

Li, W., Wei, W., Zhu, S., Zhu, J., Shi, Y., Lin, T., Hao, E., Hayek, A., Deng, H., and Ding, S. (2009). Generation of rat and human induced pluripotent stem cells by combining genetic reprogramming and chemical inhibitors. Cell Stem Cell 4, 16-19.

Liu, X., Rubin, J.S., and Kimmel, A.R. (2005). Rapid, Wnt-induced changes in GSK3beta associations that regulate beta-catenin stabilization are mediated by Galpha proteins. Curr Biol 15, 1989-1997.

Lochhead, P.A., Kinstrie, R., Sibbet, G., Rawjee, T., Morrice, N., and Cleghon, V. (2006). A chaperone-dependent GSK3beta transitional intermediate mediates activation-loop autophosphorylation. Molecular Cell 24, 627-633.

Logan, C.Y., and Nusse, R. (2004). The Wnt signaling pathway in development and disease. Annual review of cell and developmental biology 20, 781-810.

Loh, Y.H., Wu, Q., Chew, J.L., Vega, V.B., Zhang, W., Chen, X., Bourque, G., George, J., Leong, B., Liu, J., et al. (2006). The Oct4 and Nanog transcription network regulates pluripotency in mouse embryonic stem cells. Nat Genet 38, 431-440.

Ludwig, T.E., Bergendahl, V., Levenstein, M.E., Yu, J., Probasco, M.D., and Thomson, J.A. (2006). Feeder-independent culture of human embryonic stem cells. Nat Methods 3, 637-646.

Luo, J., Manning, B.D., and Cantley, L.C. (2003). Targeting the PI3K-Akt pathway in human cancer: rationale and promise. Cancer Cell 4, 257-262.

Lyashenko, N., Winter, M., Migliorini, D., Biechele, T., Moon, R.T., and Hartmann, C. (2011). Differential requirement for the dual functions of beta-catenin in embryonic stem cell self-renewal and germ layer formation. Nat Cell Biol 13, 1-10.

Macaulay, K., Doble, B.W., Patel, S., Hansotia, T., Sinclair, E.M., Drucker, D.J., Nagy, A., and Woodgett, J.R. (2007). Glycogen synthase kinase 3alpha-specific regulation of murine hepatic glycogen metabolism. Cell Metabolism 6, 329-337.

Mi, K., Dolan, P.J., and Johnson, G.V.W. (2006). The low density lipoprotein receptor-related protein 6 interacts with glycogen synthase kinase 3 and attenuates activity. J Biol Chem 281, 4787-4794.

Molofsky, A.V., Pardal, R., and Morrison, S.J. (2004). Diverse mechanisms regulate stem cell self-renewal. Current opinion in cell biology 16, 700-707.

Morin, P.J., and Weeraratna, A.T. (2003). Wnt signaling in human cancer. Cancer Treat Res 115, 169-187.

Mukai, F., Ishiguro, K., Sano, Y., and Fujita, S.C. (2002). Alternative splicing isoform of tau protein kinase I/glycogen synthase kinase 3beta. Journal of Neurochemistry 81, 1073-1083.

Nelson, W.J. (2008). Regulation of cell-cell adhesion by the cadherin-catenin complex. Biochemical Society transactions 36, 149-155.

Ng, S.S., Mahmoudi, T., Danenberg, E., Bejaoui, I., de Lau, W., Korswagen, H.C., Schutte, M., and Clevers, H. (2009). Phosphatidylinositol 3-kinase signaling does not activate the wnt cascade. Journal of Biological Chemistry 284, 35308-35313.

Nichols, J., and Smith, A. (2009). Naive and primed pluripotent states. Cell Stem Cell 4, 487-492. 
Niwa, H., Burdon, T., Chambers, I., and Smith, A. (1998). Self-renewal of pluripotent embryonic stem cells is mediated via activation of STAT3. Genes Dev 12, 2048-2060.

Ogawa, K., Nishinakamura, R., Iwamatsu, Y., Shimosato, D., and Niwa, H. (2006). Synergistic action of Wnt and LIF in maintaining pluripotency of mouse ES cells. Biochem Biophys Res Commun 343, 159-166.

Orsulic, S., and Peifer, M. (1996). Cell-cell signalling: Wingless lands at last. Curr Biol 6, 1363-1367.

Paling, N.R., Wheadon, H., Bone, H.K., and Welham, M.J. (2004). Regulation of embryonic stem cell self-renewal by phosphoinositide 3-kinase-dependent signaling. J Biol Chem 279, 48063-48070.

Pan, G., and Thomson, J.A. (2007). Nanog and transcriptional networks in embryonic stem cell pluripotency. Cell Res 17, 42-49.

Peifer, M., Pai, L.M., and Casey, M. (1994). Phosphorylation of the Drosophila adherens junction protein Armadillo: roles for wingless signal and zeste-white 3 kinase. Dev Biol 166, 543-556.

Pereira, L., Yi, F., and Merrill, B.J. (2006). Repression of Nanog gene transcription by Tcf3 limits embryonic stem cell self-renewal. Mol Cell Biol 26, 7479-7491.

Piao, S., Lee, S.-H., Kim, H., Yum, S., Stamos, J.L., Xu, Y., Lee, S.-J., Lee, J., Oh, S., Han, J.-K., et al. (2008). Direct inhibition of GSK3beta by the phosphorylated cytoplasmic domain of LRP6 in Wnt/beta-catenin signaling. PLoS ONE 3, e4046.

Popkie, A.P., Zeidner, L.C., Albrecht, A.M., D\&apos;Ippolito, A., Eckardt, S., Newsom, D.E., Groden, J., Doble, B.W., Aronow, B., McLaughlin, K.J., et al. (2010). Phosphatidylinositol 3-kinase (PI3K) signaling via glycogen synthase kinase-3 (Gsk-3) regulates DNA methylation of imprinted loci. Journal of Biological Chemistry 285, 41337-41347.

Rodda, D.J., Chew, J.L., Lim, L.H., Loh, Y.H., Wang, B., Ng, H.H., and Robson, P. (2005). Transcriptional regulation of nanog by OCT4 and SOX2. J Biol Chem 280, 24731-24737.

Rossant, J. (2001). Stem cells from the Mammalian blastocyst. Stem Cells 19, 477-482.

Sato, H., Amagai, K., Shimizukawa, R., and Tamai, Y. (2009). Stable generation of serumand feeder-free embryonic stem cell-derived mice with full germline-competency by using a GSK3 specific inhibitor. Genesis 47, 414-22.

Sato, N., Meijer, L., Skaltsounis, L., Greengard, P., and Brivanlou, A.H. (2004). Maintenance of pluripotency in human and mouse embryonic stem cells through activation of Wnt signaling by a pharmacological GSK-3-specific inhibitor. Nat Med 10, 55 - 63.

Schaffer, B., Wiedau-Pazos, M., and Geschwind, D.H. (2003). Gene structure and alternative splicing of glycogen synthase kinase 3 beta (GSK-3beta) in neural and non-neural tissues. Gene 302, 73-81.

Schulte, G., and Bryja, V. (2007). The Frizzled family of unconventional G-protein-coupled receptors. Trends Pharmacol Sci 28, 518-525.

Schweizer, L., and Varmus, H. (2003). Wnt/Wingless signaling through beta-catenin requires the function of both LRP/Arrow and frizzled classes of receptors. BMC Cell Biol 4, 4 .

Singla, D.K., Schneider, D.J., LeWinter, M.M., and Sobel, B.E. (2006). wnt3a but not wnt11 supports self-renewal of embryonic stem cells. Biochem Biophys Res Commun 345, 789-795.

Soutar, M.P.M., Kim, W.-Y., Williamson, R., Peggie, M., Hastie, C.J., McLauchlan, H., Snider, W.D., Gordon-Weeks, P.R., and Sutherland, C. (2010). Evidence that glycogen synthase kinase-3 isoforms have distinct substrate preference in the brain. Journal of Neurochemistry 115, 974-983. 
Storm, M., Kumpfmueller, B., Thompson, B., Kolde, R., Vilo, J., Hummel, O., Schulz, H., and Welham, M.J. (2009). Characterization of the Phosphoinositide 3-Kinase-Dependent Transcriptome in Murine Embryonic Stem Cells: Identification of Novel Regulators of Pluripotency. Stem Cells 27, 764-775.

Storm, M.P., Bone, H.K., Beck, C.G., Bourillot, P.Y., Schreiber, V., Damiano, T., Nelson, A., Savatier, P., and Welham, M.J. (2007). Regulation of Nanog expression by phosphoinositide 3-kinase-dependent signaling in murine embryonic stem cells. J Biol Chem 282, 6265-6273.

Sutherland, C., and Cohen, P. (1994). The alpha-isoform of glycogen synthase kinase-3 from rabbit skeletal muscle is inactivated by p70 S6 kinase or MAP kinase-activated protein kinase-1 in vitro. FEBS Lett 338, 37-42.

Taelman, V.F., Dobrowolski, R., Plouhinec, J.-L., Fuentealba, L.C., Vorwald, P.P., Gumper, I., Sabatini, D.D., and De Robertis, E.M. (2010). Wnt signaling requires sequestration of glycogen synthase kinase 3 inside multivesicular endosomes. Cell 143, 1136-1148.

Takahashi-Tezuka, M., Yoshida, Y., Fukada, T., Ohtani, T., Yamanaka, Y., Nishida, K., Nakajima, K., Hibi, M., and Hirano, T. (1998). Gab1 acts as an adapter molecule linking the cytokine receptor gp130 to ERK mitogen-activated protein kinase. Mol Cell Biol 18, 4109-4117.

Takao, Y., Yokota, T., and Koide, H. (2007). Beta-catenin up-regulates Nanog expression through interaction with Oct-3/4 in embryonic stem cells. Biochemical and biophysical research communications 353, 699-705.

Tamai, K., Semenov, M., Kato, Y., Spokony, R., Liu, C., Katsuyama, Y., Hess, F., SaintJeannet, J.P., and He, X. (2000). LDL-receptor-related proteins in Wnt signal transduction. Nature 407, 530-535.

ter Haar, E., Coll, J.T., Austen, D.A., Hsiao, H.M., Swenson, L., and Jain, J. (2001). Structure of GSK3beta reveals a primed phosphorylation mechanism. Nat Struct Biol 8, 593-596.

Tesar, P.J., Chenoweth, J.G., Brook, F.A., Davies, T.J., Evans, E.P., Mack, D.L., Gardner, R.L., and Mckay, R.D.G. (2007). New cell lines from mouse epiblast share defining features with human embryonic stem cells. Nature 448, 196-199.

Thornton, T.M., Pedraza-Alva, G., Deng, B., Wood, C.D., Aronshtam, A., Clements, J.L., Sabio, G., Davis, R.J., Matthews, D.E., Doble, B., et al. (2008). Phosphorylation by p38 MAPK as an alternative pathway for GSK3beta inactivation. Science 320, 667670.

Torres, M.A., Eldar-Finkelman, H., Krebs, E.G., and Moon, R.T. (1999). Regulation of ribosomal S6 protein kinase-p90(rsk), glycogen synthase kinase 3, and beta-catenin in early Xenopus development. Mol Cell Biol 19, 1427-1437.

Vallier, L., Alexander, M., and Pedersen, R.A. (2005). Activin/Nodal and FGF pathways cooperate to maintain pluripotency of human embryonic stem cells. Journal of Cell Science 118, 4495-4509.

Van Amerongen, R. (2005). Frat is dispensable for canonical Wnt signaling in mammals. Genes \& Development 19, 425-430.

Wagner, R.T., Xu, X., Yi, F., Merrill, B.J., and Cooney, A.J. (2010). Canonical Wnt/ $\beta$-catenin regulation of liver receptor homolog-1 mediates pluripotency gene expression. Stem Cells 28, 1794-1804.

Watanabe, S., Umehara, H., Murayama, K., Okabe, M., Kimura, T., and Nakano, T. (2006). Activation of Akt signaling is sufficient to maintain pluripotency in mouse and primate embryonic stem cells. Oncogene 25, 2697-2707. 
Wehrli, M., Dougan, S.T., Caldwell, K., O'Keefe, L., Schwartz, S., Vaizel-Ohayon, D., Schejter, E., Tomlinson, A., and DiNardo, S. (2000). arrow encodes an LDLreceptor-related protein essential for Wingless signalling. Nature 407, 527-530.

Woodgett, J.R. (1990). Molecular cloning and expression of glycogen synthase kinase3/factor A. EMBO J 9, 2431-2438.

Woodgett, J.R., Davison, M.T., and Cohen, P. (1983). The calmodulin-dependent glycogen synthase kinase from rabbit skeletal muscle. Purification, subunit structure and substrate specificity. Eur J Biochem 136, 481-487.

Wray, J., Kalkan, T., Gomez-Lopez, S., Eckardt, D., Cook, A., Kemler, R., and Smith, A. (2011). Inhibition of glycogen synthase kinase-3 alleviates Tcf3 repression of the pluripotency network and increases embryonic stem cell resistance to differentiation. Nature Cell Biology 13, 1-9.

Wu, G., Huang, H., Garcia Abreu, J., and He, X.C. (2009). Inhibition of GSK3 phosphorylation of beta-catenin via phosphorylated PPPSPXS motifs of Wnt coreceptor LRP6. PLoS ONE 4, e4926.

Xu, R.H., Chen, X., Li, D.S., Li, R., Addicks, G.C., Glennon, C., Zwaka, T.P., and Thomson, J.A. (2002). BMP4 initiates human embryonic stem cell differentiation to trophoblast. Nat Biotechnol 20, 1261-1264.

Yamada, S., Pokutta, S., Drees, F., Weis, W.I., and Nelson, W.J. (2005). Deconstructing the cadherin-catenin-actin complex. Cell 123, 889-901.

Yamamoto, H., Kishida, S., Kishida, M., Ikeda, S., Takada, S., and Kikuchi, A. (1999). Phosphorylation of axin, a Wnt signal negative regulator, by glycogen synthase kinase-3beta regulates its stability. J Biol Chem 274, 10681-10684.

Yi, F., Pereira, L., Hoffman, J.A., Shy, B.R., Yuen, C.M., Liu, D.R., and Merrill, B.J. (2011). Opposing effects of Tcf3 and Tcf1 control Wnt stimulation of embryonic stem cell self-renewal. Nature Cell Biology 13, 1-11.

Yi, F., Pereira, L., and Merrill, B.J. (2008). Tcf3 Functions as a Steady State Limiter of Transcriptional Programs of Mouse Embryonic Stem Cell Self Renewal. Stem Cells 26, 1951-60.

Ying, Q.L., Nichols, J., Chambers, I., and Smith, A. (2003). BMP induction of Id proteins suppresses differentiation and sustains embryonic stem cell self-renewal in collaboration with STAT3. Cell 115, 281-292.

Ying, Q.L., and Smith, A.G. (2003). Defined conditions for neural commitment and differentiation. Methods Enzymol 365, 327-341.

Ying, Q.L., Wray, J., Nichols, J., Batlle-Morera, L., Doble, B., Woodgett, J., Cohen, P., and Smith, A. (2008). The ground state of embryonic stem cell self-renewal. Nature 453, 519-523.

Yuan, T.L., and Cantley, L.C. (2008). PI3K pathway alterations in cancer: variations on a theme. Oncogene 27, 5497-5510.

Zeng, X., Huang, H., Tamai, K., Zhang, X., Harada, Y., Yokota, C., Almeida, K., Wang, J., Doble, B., Woodgett, J., et al. (2008). Initiation of Wnt signaling: control of Wnt coreceptor Lrp6 phosphorylation/activation via frizzled, dishevelled and axin functions. Development 135, 367-375.

Zeng, X., Tamai, K., Doble, B., Li, S., Huang, H., Habas, R., Okamura, H., Woodgett, J., and He, X. (2005). A dual-kinase mechanism for Wnt co-receptor phosphorylation and activation. Nature 438, 873-877.

Zhou, J., Lal, H., Chen, X., Shang, X., Song, J., Li, Y., Kerkelä, R., Doble, B.W., Macaulay, K., DeCaul, M., et al. (2010). GSK-3alpha directly regulates beta-adrenergic signaling and the response of the heart to hemodynamic stress in mice. J Clin Invest 120, 2280-2291. 


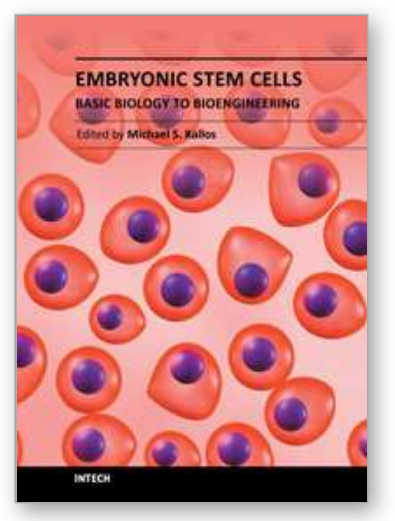

\author{
Embryonic Stem Cells - Basic Biology to Bioengineering \\ Edited by Prof. Michael Kallos
}

ISBN 978-953-307-278-4

Hard cover, 478 pages

Publisher InTech

Published online 15, September, 2011

Published in print edition September, 2011

Embryonic stem cells are one of the key building blocks of the emerging multidisciplinary field of regenerative medicine, and discoveries and new technology related to embryonic stem cells are being made at an ever increasing rate. This book provides a snapshot of some of the research occurring across a wide range of areas related to embryonic stem cells, including new methods, tools and technologies; new understandings about the molecular biology and pluripotency of these cells; as well as new uses for and sources of embryonic stem cells. The book will serve as a valuable resource for engineers, scientists, and clinicians as well as students in a wide range of disciplines.

\title{
How to reference
}

In order to correctly reference this scholarly work, feel free to copy and paste the following:

Bradley W. Doble, Kevin F. Kelly and James R. Woodgett (2011). Molecular Mechanisms Underlying Pluripotency and Lineage Commitment - The Role of GSK-3, Embryonic Stem Cells - Basic Biology to Bioengineering, Prof. Michael Kallos (Ed.), ISBN: 978-953-307-278-4, InTech, Available from: http://www.intechopen.com/books/embryonic-stem-cells-basic-biology-to-bioengineering/molecularmechanisms-underlying-pluripotency-and-lineage-commitment-the-role-of-gsk-3

\section{INTECH}

open science | open minds

\section{InTech Europe}

University Campus STeP Ri

Slavka Krautzeka 83/A

51000 Rijeka, Croatia

Phone: +385 (51) 770447

Fax: +385 (51) 686166

www.intechopen.com

\section{InTech China}

Unit 405, Office Block, Hotel Equatorial Shanghai

No.65, Yan An Road (West), Shanghai, 200040, China

中国上海市延安西路65号上海国际贵都大饭店办公楼 405 单元

Phone: +86-21-62489820

Fax: +86-21-62489821 
(C) 2011 The Author(s). Licensee IntechOpen. This chapter is distributed under the terms of the Creative Commons Attribution-NonCommercialShareAlike-3.0 License, which permits use, distribution and reproduction for non-commercial purposes, provided the original is properly cited and derivative works building on this content are distributed under the same license. 